\title{
Estimation of Exchange Rate Volatility using APARCH-type Models: A Case Study of Indonesia (2010-2015)
}

\author{
Didit B. Nugroho, Bambang Susanto, Saragah R. Pratama \\ Dept. of Mathematics, Satya Wacana Christian University, Indonesia \\ E-mail: didit.budinugroho@staff.uksw.edu
}

Received: September 3, 2016; Accepted: December 18, 2016; Published: March 2, 2017

Permalink/DOI: http://dx.doi.org/10.17977/um002v9i12017p065

\begin{abstract}
Volatiliy measurement and modeling is an important aspect in many areas of finance. The main purpose of this study is to apply seven APARCH-type models with $(1,1)$ lags to investigate the behavior of exchange rate volatility for the EUR, JPY, and USD selling exchange rates to IDR for the duration from January 2010 to December 2015. The competing models include ARCH, GARCH, TARCH, TS-ARCH, GJR-GARCH, NARCH, and APARCH used with Gaussian normal distribution. In order to estimate the model parameters, this study applies the Bayesian inference using the adaptive random walk Metropolis method in the MCMC algorithm. Empirical results based on the deviance information criterion indicate that the GARCH $(1,1)$, APARCH $(1,1)$, and TARCH $(1,1)$ models provide the best fit for the EUR, JPY, and USD data, respectively. In those models, both the JPY and USD data have significant negative leverage effect at the 99\% credible level. Moreover, the JPY returns also have significant Taylor effect in return volatility at the $99 \%$ credible level.
\end{abstract}

Keywords: APARCH, ARWM, IDR exchange rate, MCMC, volatility JEL Classification: C30, F31

\section{INTRODUCTION}

Volatility of asset returns has been widely used in financial market. Volatility, of stock prices or exchange rates, can be considered as a measurement of the risk for the securities based on the fluctuation of the asset returns. Abdalla \& Winker (2012) defined the volatility as a statistical measure of the spread of returns on a market index or a specific security, and it is usually measured by using the standard deviation of returns. As shown in many studies, the high volatility of exchange rate returns leads to higher risk for investors, traders, and policy makers.

In general, high frequency financial returns -weekly, daily, or minutes- is heteroskedastic, i.e. the value of volatility is changing over times. On the basis of the fact, Engle (1982) proposed ARCH (autoregressive conditional heteroscedasticity) model that has been well studied in financial literature. This model was extended to GARCH (generalized ARCH) model by Bollerslev (1986). The ARCH/GARCH models can capture the volatility clustering and fat tail (leptokurtic) successfully, but they both fail to capture the leverage effect, which is common phenomenon in financial markets. An extension of the GARCH model accommodating the above three effects is the asymmetric power GARCH 
(APARCH) model from Ding et al. (1993). Furthermore, Danielsson (2011) states that the APARCH model combines two effects: (1) leverage effect: asymmetry in the impact of positive and negative lagged returns, and (2) allowing power in the volatility calculation to be flexible.

In this study, a family of APARCH model is fitted to the Euro (EUR), Japanese yen (JPY), and US dollar (USD) selling exchange rates to the Indonesian rupiah (IDR) for the duration from January 2010 to December 2015. We construct Markov chain Monte Carlo (MCMC) algorithm based on the adaptive random walk Metropolis method to estimate the APARCH-type models. Hereafter, their estimation results are compared to obtain the best fitting model for each data on the basis of the deviance information criterion (DIC).

\section{LITERATURE REVIEW}

There is a large number of literature on the modeling and forecasting of return volatility. In recent years, Nugroho \& Morimoto (2014, 2015, 2016) applied the stochastic volatility models to stock markets. In the case of Indonesia foreign exchange markets, however, there is relatively very few literature and research applying the ARCH/GARCH models. For example, Safrudin et al. (2015); Salim et al. (2016), and Saputri et al. (2016) studied the behavior of EUR and JPY selling exchange rates to the IDR during the period 2009-2014 using ARCH/GARCH models with non-normal distributions for returns errors. Their results confirm that a non-normal distribution for returns errors in ARCH/ GARCH models is appropriate for the data. This study, on the other hand, will consider only the use of normal distribution for returns errors and focus on the generalization of the GARCH models to APARCH-type models.

\section{METHOD}

\section{Data Used for the Analysis}

As Salvatore (2013) explains, there are five dominant international currencies in the world economy in 2010, i.e. USD, EUR, JPY, GBP, and CHF. The data analyzed in this study are the selling exchange rates for the EUR, JPY, and GBP to the IDR. The data sets were obtained from Bank Indonesia's internet website (http://www.bi.go.id) covering the six years from January 2010 to December 2015 on a daily basis, excluding weekends and holidays. Hereafter, we denote the $Y$ selling exchange rate to the $X$ by $X / Y$, meaning that the number of $X \mathrm{~s}$ are required by buyer to purchase one $Y$ from trader.

\section{Models Used in This Study}

On the basis of the assumption that an asset price follows geometric Brownian motion, returns can be expressed by (Tsay, 2005):

$$
R_{t}=\ln \left(\frac{S_{t}}{S_{t-1}}\right)=\mu+\varepsilon_{t}, \varepsilon_{t} \sim N\left(0, \sigma_{t}^{2}\right),
$$

where $\mu$ is the average of returns and $S_{t}$ is the aset price at time $t$. Furthermore, this study assumes that $\mu=0$ and the returns are expressed in percentage as folows:

$$
R_{t}=100 \times \ln \left(\frac{S_{t}}{S_{t-1}}\right) .
$$

In practice it is assumed that the returns are not serially correlated. 
Models that offers more flexibility than GARCH models are APARCHtype models, where $\sigma_{t}^{2}$ in the GARCH model is replaced by $\sigma_{t}^{\delta}$, with $\delta>0$. The conditional volatility dynamics of these models are expressed by

$$
\sigma_{t}^{\delta}=\omega+\sum_{i=1}^{p} \alpha_{i}\left(\left|R_{t-i}\right|-\gamma_{i} R_{t-i}\right)^{\delta}+\sum_{j=1}^{q} \beta_{j} \sigma_{t-j}^{\delta},
$$

where $t=1,2, \ldots, T, \omega>0, \alpha_{i} \geq 0, \beta_{i} \geq 0, \delta>0$, and $-1<\gamma_{i}<1$. Here, $\alpha$ and $\beta$ are the ARCH and GARCH coefficients respectively, $\gamma$ is the leverage effect between volatility and returns when $\gamma \neq 0$, and $\delta$ is the Taylor (power) effect after Taylor (1986), when $\delta \neq 1$. Taylor effect accommodates the fact that absolute returns sometimes have stronger autocorrelation than squared returns. The idea behind the allowing $\delta$ to take the form of a free parameter arose from the fact that, the assumption of normality in modeling finansial data, which restricts $\delta$ to either 1 or 2 , is often unrealistic due to significant skewness and kurtosis (Longmore and Robinson, 2004).

The effect of $R_{t-i}$ upon $\sigma_{t}$ is through the function $k_{y_{i}}\left(R_{t-i}\right)$, where $k_{y_{i}}\left(R_{t-i}\right)=\left|R_{t-i}\right|-\gamma_{i} R_{t-i}$. If $\gamma>0$, then $k_{y_{i}}\left(-R_{t-i}\right)>k_{y_{i}}\left(R_{t-i}\right)$ for any $R_{t-i}>0$, so there is a leverage effect, meaning that past "bad news" (negative returns) have a stronger impact on current volatility than past "good news" (positive returns). If $\gamma<0$, then $k_{y_{i}}\left(R_{t-i}\right)>k_{y_{i}}\left(-R_{t-i}\right)$, so there is a leverage effect in the opposite direction to what is expected, meaning that past positive returns increase current volatility than past negative returns.

The APARCH model is a nested model including as special cases (Laurent, 2003):

When $\delta=2, \beta=0$, and $\gamma=0$, the model is ARCH.

When $\delta=2$ and $\gamma=0$, the model is GARCH.

When $\delta=1$ and $\gamma=0$, the model is TS-GARCH.

When $\delta=2$, the model is GJR-GARCH.

When $\delta=1$, the model is TARCH.

When $\beta=0$ and $\gamma=0$, the model is NARCH.

This study applies the above models to real data and compares their modeling performance. By using the GARCH $(1,1)$ model, Ruppert (2011) empirically showed that autocorrelation decays slowly decrease after one lag. This capability appears to be the main reason that the GARCH model with autocorrelation lag-1 fits so many financial time series. Therefore, this study takes $p=1$ and $q \leq 1$ in the APARCH-type models.

\section{MCMC Method for APARCH(1,1)}

Nugroho \& Morimoto (2014) pointed out that the implementation of MCMC method involves two steps. The first step is to construct Markov chain that has as an equilibrium distribution which matches the conditional posterior distribution. The second step is to summarize posterior distribution of the parameter as MCMC output, using the Monte Carlo method.

Let $\boldsymbol{R}=\left(R_{1}, R_{2}, \ldots, R_{T}\right)$ denotes the observation vector, and $\theta=$ $(\omega, \alpha, \beta, \gamma, \delta)$ the parameter vector. By applying Bayes' rule, the posterior distribution of the parameters given the observed data can be written as:

$$
p(\theta \mid \sigma, \boldsymbol{R})=L(\boldsymbol{R} \mid \theta) p(\theta),
$$

where 


$$
L(\boldsymbol{R} \mid \theta)=\prod_{t=1}^{T} \frac{1}{\sqrt{2 \pi \sigma_{t}^{2}}} \exp \left(-\frac{R_{t}^{2}}{2 \sigma_{t}^{2}}\right)
$$

and $p(\theta)$ is a prior distribution on $\theta$.

MCMC methods have been widely used for estimation purposes in practical finance applications. One of the most common MCMC methods in practical use is the random walk Metropolis (RWM) which has been extended to the Adaptive RWM (ARWM) method to improve the efficiency of the method. Suppose $y_{n}$ is a real sequence, the ARWM scheme is employed as follows (Atachade and Rosenthal, 2005):

(i) Initialize $\theta_{0}$ dan $g_{0}$.

(ii) Let $n \geq 0$, given $\theta_{n}$ and $g_{n}$.

a. Draw a proposal $y_{n+1}=\theta_{n}+\eta_{t}$ and $x \sim U(0,1)$, where $\eta_{t} \sim N\left(g_{n}, 1\right)$.

b. Calculate the Metropolis ratio:

$$
r\left(\theta_{n}, \theta_{n+1}\right)=\frac{p\left(\theta_{n+1} \mid \boldsymbol{R}\right)}{p\left(\theta_{n} \mid \boldsymbol{R}\right)}
$$

and the acceptance probability $\alpha\left(\theta_{n}, \theta_{n+1}\right)=\min \left\{1, r\left(\theta_{n}, \theta_{n+1}\right)\right\}$.

c. If $x \leq \alpha\left(\theta_{n}, \theta_{n+1}\right)$, then $\theta_{n+1}=y_{n+1}$; otherwise, $\theta_{n+1}=\theta_{n}$.

(iii) Let $g_{i} \in\left[g_{\min }, g_{\max }\right]$ and calculate:

$$
v=\max \left\{g_{\min }, g_{n}+\frac{\frac{m(\theta)}{n+1}-\bar{\tau}}{(n+1)^{\lambda}}\right\},
$$

where $m(\theta)$ denotes the number of accepted proposals up to iteration- $(n+$ 1)th.

We set:

If $v>g_{\text {max }}$, then $g_{n+1}=g_{\text {max }}$; otherwise, $g_{n+1}=g_{n}$.

$$
g_{\text {min }}=10^{-5}, g_{\text {maks }}=10, \bar{\tau}=0,44, \lambda=0,6
$$

where $\bar{\tau}$ was chosen to make the acceptance rate of proposals as close as possible to 0.44 (Roberts \& Rosenthal, 2009). As Atachade \& Rosenthal (2005) explain, the choice of the scaling parameter $g_{i}$ has a large effect on the algorithm's mixing time. Intuitively, if $g_{i}$ is too small, the resulting algorithm will make very small moves, resulting in a poor mixing time. On the other hand, if $g_{i}$ is too large, then large moves will usually be proposed, and these are likely to be rejected so the algorithm will again mix poorly.

\section{RESULT AND DISCUSSION \\ Descriptive Statistics of the Data}

In this study, the proposed models are fitted to daily returns of IDR/EUR, IDR/JPY, and IDR/USD during the six years period from January 2010 to December 2015. The dataset consists of 1472 observations, excluding weekends and holidays. Figure 1 displays the time series plots of daily exchange rate and its returns (in percent). Meanwhile, the descriptive statistics for returns, such as mean and standard deviation (SD), Jarque-Bera(JB) normality test, and Ljung-Box (LB) autocorrelation test are summarized in Table 1. Normality and autocorrelation tests show that all returns are neither normally distributed nor 
serially correlated for 8 lags. In order to provide a principal empirical structure for developing more general models, the non-normality distribution are avoided.
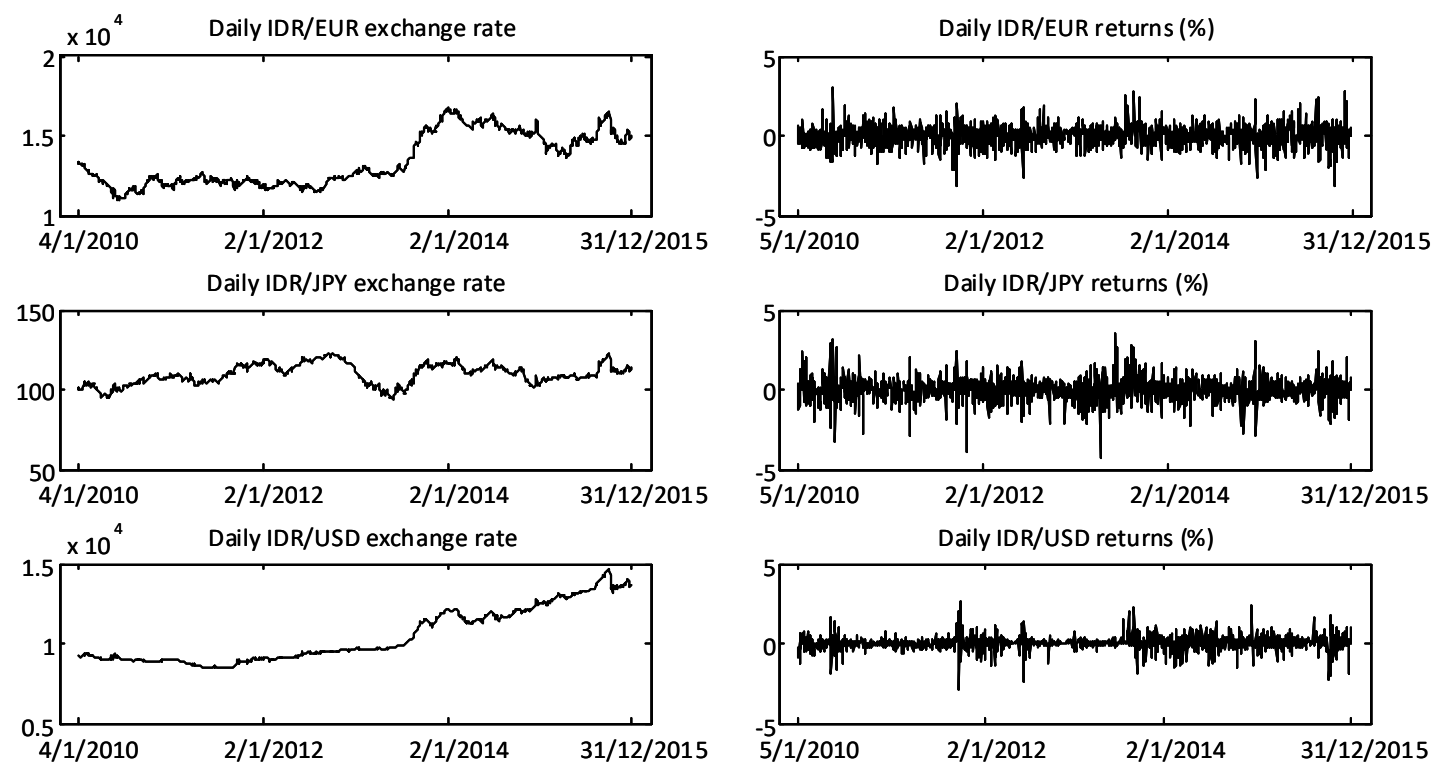

Figure 1. Time series plots for daily selling exchange rate and their returns (in percent).

Source: Authors' calculation.

Table 1. Descriptive statistics of the daily returns of the IDR/EUR, IDR/JPY, and IDR/USD (January 2010 to December 2015).

\begin{tabular}{lccccccc}
\hline Returns & $\begin{array}{c}\text { Number of } \\
\text { observation }\end{array}$ & Mean & SD & Min. & Max. & $\begin{array}{c}\text { JB stat. } \\
\text { (normality) }\end{array}$ & $\begin{array}{c}\text { LB stat. } \\
\text { (lag-8 autocorr.) }\end{array}$ \\
\hline IDR/EUR & 1471 & 0.008 & 0.680 & -3.199 & 3.092 & $184.2(\mathrm{no})$ & $6.72(\mathrm{no})$ \\
\hline IDR/JPY & 1469 & 0.009 & 0.746 & -4.284 & 3.499 & $666.4(\mathrm{no})$ & $9.97(\mathrm{no})$ \\
\hline IDR/USD & 1415 & 0.028 & 0.461 & -2.858 & 2.713 & $2237.4(\mathrm{no})$ & $7.99(\mathrm{no})$ \\
\hline
\end{tabular}

Source: Authors' calculation

\section{Stationarity Test}

This study has applied the Augmented Dickey-Fuller (ADF) test (Dickey dan Fuller, 1981) to investigate whether the exchange rate and its returns series are stationary. The results reported in Table 2 indicate that the test does not reject the null hypothesis of a unit root at all confidence levels for all exchange rate series, but the test allows rejecting the null hypothesis for the returns series. It means that the returns are stationary series.

Table 2. ADF unit root test output for the exchange rate series and their returns series.

\begin{tabular}{cccc}
\hline Series & IDR/EUR & IDR/JPY & IDR/USD \\
\hline Selling exchange rate & -0.87 & -2.50 & 0.87 \\
\hline Returns & -36.55 & -39.37 & -37.83 \\
\hline
\end{tabular}

Source: Authors' calculation.

Notes: $1 . H_{0}$ is a unit root, $H_{A}$ is stationarity.

2. ADF test include a constant term without trend.

3. Maximum lag length was set to 22 .

4. Critical values for unit root tests at $99 \%, 95 \%$, and $90 \%$ confidence intervals are respectively $-3.45,-2.87$, and -2.57 . 


\section{Heteroscedasticity Test}

Since the purpose of this study is to analyze volatility of returns series, it is necessary to perform a test for heteroscedasticity of residuals. The test was implemented in MATLAB with "archtest" function for the return residuals, i.e the difference between returns and its average. The results, as shown in Table 3, can be summarized as follows: $\mathrm{H}=1$, the p-value is less than 0.05 , the ARCH test statistics is greater than the critical value at $95 \%$ confidence level. These imply that there is a strong evidence for rejecting the null hypothesis of no ARCH effect. The rejection indicates the existence of $\mathrm{ARCH}$ effects in the return residual series and therefore the variance of all observed returns is not constant.

Table 3. MATLAB output for the ARCH effect test of return residuals.

\begin{tabular}{cccccccccc}
\hline & \multicolumn{3}{c}{ IDR/EUR } & \multicolumn{3}{c}{ IDR/JPY } & \multicolumn{3}{c}{ IDR/USD } \\
\hline Lag & 10 & 15 & 20 & 10 & 15 & 20 & 10 & 15 & 20 \\
\hline H & 1 & 1 & 1 & 1 & 1 & 1 & 1 & 1 & 1 \\
\hline P-value & 0 & 0 & 0 & 0 & 0 & 0 & 0 & 0 & 0 \\
\hline ARCH statistics & 48.4 & 51.7 & 51.9 & 59.9 & 62.6 & 63.0 & 239.4 & 252.2 & 264.5 \\
\hline Critical value & 18.3 & 25.0 & 31.4 & 18.3 & 25.0 & 31.4 & 18.3 & 25.0 & 31.4 \\
\hline
\end{tabular}

Source: Authors' calculation.

Notes: $1 . H_{0}:$ no ARCH effect is present.

2. $\mathrm{H}=1$ indicates rejection of $H_{0}$.

3. Critical values are computed at $95 \%$ confidence interval.

\section{Empirical Results}

All empirical results were obtained via implementation of our own scripts in Matlab. For all cases, this study employed the MCMC simulation for 15000 iterations. In this process, we discard the first 5000 iterations and store the remaining 10000 iterations to contribute to the required statistics, such as the mean, standard deviation, 95\% highest posterior density interval, and the integrated autocorrelation time (IACT) as an indicator of inefficiency sampler. IACT can be roughly interpreted as the number of iterations required so as to produce independent draws. A value of one indicates that the sampler delivers uncorrelated draws set, while large values deliver slowly decaying correlations as well as slow convergence. Tables 4-6 summarize the empirical results for the IDR/EUR, IDR/JPY, and IDR/USD returns data sets, respectively. Overall, the IACT values indicate that the ARWM method provides sufficiently efficient estimation for all applied models.

Table 4. Results of MCMC estimation for the models adopting IDR/EUR returns, the conditional DIC estimates, and the $\mathrm{pD}$ (effective number of parameters) estimates.

\begin{tabular}{ccccccccc}
\hline $\begin{array}{l}\text { Para- } \\
\text { meter }\end{array}$ & Statistics & \multicolumn{7}{c}{ Model } \\
\cline { 3 - 8 } & ARCH & GARCH & TARCH & $\begin{array}{c}\text { TS- } \\
\text { GARCH }\end{array}$ & $\begin{array}{c}\text { GJR- } \\
\text { GARCH }\end{array}$ & NARCH APARCH \\
\hline $\boldsymbol{\omega}$ & Mean & 0.402 & 0.027 & 0.100 & 0.162 & 0.037 & 0.346 & 0.277 \\
\cline { 2 - 8 } & SD & 0.018 & 0.012 & 0.019 & 0.026 & 0.014 & 0.115 & 0.045 \\
\cline { 2 - 8 } & LB & 0.368 & 0.006 & 0.065 & 0.112 & 0.009 & 0.143 & 0.193 \\
\cline { 2 - 8 } & UB & 0.439 & 0.050 & 0.133 & 0.208 & 0.062 & 0.557 & 0.363 \\
\cline { 2 - 8 } & IACT & 14.7 & 315.0 & 368.7 & 385.0 & 305.4 & 319.3 & 467.7 \\
\hline $\boldsymbol{\alpha}$ & Mean & 0.135 & 0.056 & 0.086 & 0.060 & 0.062 & 0.115 & 0.106 \\
\cline { 2 - 8 } & SD & 0.034 & 0.013 & 0.017 & 0.012 & 0.015 & 0.040 & 0.025 \\
\hline
\end{tabular}




\begin{tabular}{|c|c|c|c|c|c|c|c|c|}
\hline \multirow{5}{*}{$\begin{array}{l}\text { Para- } \\
\text { meter }\end{array}$} & Statistics & \multicolumn{7}{|c|}{ Model } \\
\hline & & ARCH & GARCH & TARCH & $\begin{array}{c}\text { TS- } \\
\text { GARCH }\end{array}$ & $\begin{array}{c}\text { GJR- } \\
\text { GARCH }\end{array}$ & NARCH & APARCH \\
\hline & LB & 0.072 & 0.030 & 0.057 & 0.038 & 0.036 & 0.038 & 0.054 \\
\hline & UB & 0.205 & 0.083 & 0.124 & 0.083 & 0.094 & 0.192 & 0.154 \\
\hline & IACT & 15.0 & 187.5 & 150.9 & 78.4 & 146.3 & 131.2 & 95.2 \\
\hline \multirow[t]{5}{*}{$\boldsymbol{\beta}$} & Mean & 0 & 0.884 & 0.785 & 0.717 & 0.856 & 0 & 0.526 \\
\hline & SD & & 0.035 & 0.033 & 0.041 & 0.039 & & 0.109 \\
\hline & LB & & 0.815 & 0.731 & 0.640 & 0.788 & & 0.313 \\
\hline & UB & & 0.943 & 0.846 & 0.794 & 0.935 & & 0.705 \\
\hline & IACT & & 342.9 & 380.4 & 394.1 & 324.4 & & 452.9 \\
\hline \multirow[t]{5}{*}{$\gamma$} & Mean & 0 & 0 & -0.143 & 0 & -0.063 & 0 & -0.027 \\
\hline & SD & & & 0.097 & & 0.066 & & 0.122 \\
\hline & LB & & & -0.338 & & -0.199 & & -0.278 \\
\hline & UB & & & 0.040 & & 0.068 & & 0.207 \\
\hline & IACT & & & 4.8 & & 7.7 & & 7.7 \\
\hline \multirow[t]{5}{*}{$\delta$} & Mean & 2 & 2 & 1 & 1 & 2 & 2.528 & 1.472 \\
\hline & SD & & & & & & 0.895 & 0.230 \\
\hline & LB & & & & & & 1.119 & 1.041 \\
\hline & UB & & & & & & 4.310 & 1.926 \\
\hline & IACT & & & & & & 339.5 & 245.0 \\
\hline \multicolumn{2}{|c|}{ Persistence } & - & 0.941 & 0.801 & 0.778 & 0.887 & - & 0.638 \\
\hline \multicolumn{2}{|c|}{$\begin{array}{c}\text { Conditional } \\
\text { DIC (SD) }\end{array}$} & $\begin{array}{l}3012.1 \\
(0.03)\end{array}$ & $\begin{array}{l}2996.7 \\
(0.58)\end{array}$ & $\begin{array}{c}3004.6 \\
(1.52)\end{array}$ & $\begin{array}{c}2998.7 \\
(0.79)\end{array}$ & $\begin{array}{c}2998.6 \\
(0.68)\end{array}$ & $\begin{array}{l}3014.9 \\
(0.07)\end{array}$ & $\begin{array}{c}3009.8 \\
(0.57)\end{array}$ \\
\hline \multicolumn{2}{|c|}{ pD } & 2 & 5 & 6 & 4 & 7 & 3 & 7 \\
\hline \multicolumn{2}{|c|}{ Rank } & 6 & 1 & 4 & 3 & 2 & 7 & 5 \\
\hline
\end{tabular}

Source: Authors' calculation from IDR/EUR returns.

We first consider the feature of leverage effect in the TARCH, GJRGARCH, and APARCH models. In the case of applying the returns of the EUR selling exchange rate to the IDR, the 95\% HPD intervals of $\gamma$ include 0 , indicating that the data do not provide statistically significant evidence in support of the leverage effect. Meanwhile, in the case of the IDR/JPY and IDR/USD returns data, the leverage parameter is found to be statistically negative significant in the APARCH model, which implies the presence of leverage effect. Although not reported, we find that even 99\% HPD interval of $\gamma$ excludes 0 . It indicates that the IDR/JPY and IDR/USD returns volatilities are greater after bad news (negative return) than after good news (positive return).

Table 5. Results of MCMC estimation for the models adopting IDR/JPY returns, the conditional DIC estimates, and the $\mathrm{pD}$ (effective number of parameters) estimates.

\begin{tabular}{ccccccccc}
\hline $\begin{array}{c}\text { Para- Statistics } \\
\text { meter }\end{array}$ & \multicolumn{7}{c}{ Model } \\
\cline { 2 - 8 } & ARCH & GARCH & TARCH & $\begin{array}{c}\text { TS- } \\
\text { GARCH }\end{array}$ & $\begin{array}{c}\text { GJR- } \\
\text { GARCH }\end{array}$ & NARCH & APARCH \\
\hline $\boldsymbol{\omega}$ & Mean & 0.432 & 0.034 & 0.073 & 0.084 & 0.041 & 0.655 & 0.127 \\
\cline { 2 - 8 } & SD & 0.022 & 0.015 & 0.013 & 0.015 & 0.010 & 0.062 & 0.024 \\
\cline { 2 - 8 } & LB & 0.390 & 0.010 & 0.049 & 0.057 & 0.022 & 0.531 & 0.081 \\
\cline { 2 - 8 } & UB & 0.476 & 0.066 & 0.101 & 0.124 & 0.060 & 0.773 & 0.169 \\
\hline \multirow{2}{*}{$\boldsymbol{~ I A C T ~}$} & 8.4 & 263.9 & 294.2 & 384.0 & 122.6 & 229.8 & 433.1 \\
\cline { 2 - 8 } & Mean & 0.255 & 0.097 & 0.144 & 0.058 & 0.105 & 0.233 & 0.121 \\
\cline { 2 - 8 } & SD & 0.048 & 0.024 & 0.018 & 0.009 & 0.019 & 0.039 & 0.016 \\
\cline { 2 - 8 } & LB & 0.166 & 0.052 & 0.109 & 0.041 & 0.067 & 0.154 & 0.091 \\
\hline & UB & 0.352 & 0.148 & 0.182 & 0.078 & 0.142 & 0.302 & 0.156 \\
\hline
\end{tabular}




\begin{tabular}{|c|c|c|c|c|c|c|c|c|}
\hline \multirow{3}{*}{$\begin{array}{l}\text { Para- } \\
\text { meter }\end{array}$} & \multirow{2}{*}{ Statistics } & \multicolumn{7}{|c|}{ Model } \\
\hline & & ARCH & GARCH & TARCH & $\begin{array}{c}\text { TS- } \\
\text { GARCH }\end{array}$ & $\begin{array}{c}\text { GJR- } \\
\text { GARCH }\end{array}$ & NARCH & APARCH \\
\hline & IACT & 9.968 & 212.5 & 128.8 & 171.9 & 79.5 & 157.2 & 123.6 \\
\hline \multirow[t]{5}{*}{$\boldsymbol{\beta}$} & Mean & 0 & 0.844 & 0.792 & 0.841 & 0.817 & 0 & 0.753 \\
\hline & SD & & 0.045 & 0.023 & 0.026 & 0.028 & & 0.032 \\
\hline & LB & & 0.748 & 0.748 & 0.780 & 0.768 & & 0.693 \\
\hline & UB & & 0.921 & 0.834 & 0.890 & 0.872 & & 0.812 \\
\hline & IACT & & 281.7 & 319.4 & 390.5 & 136.7 & & 460.2 \\
\hline \multirow[t]{5}{*}{$\gamma$} & Mean & 0 & 0 & -0.329 & 0 & -0.324 & 0 & -0.363 \\
\hline & SD & & & 0.090 & & 0.076 & & 0.085 \\
\hline & LB & & & -0.502 & & -0.477 & & -0.544 \\
\hline & UB & & & -0.153 & & -0.178 & & -0.208 \\
\hline & IACT & & & 12.9 & & 12.5 & & 18.2 \\
\hline \multirow[t]{5}{*}{$\delta$} & Mean & 2 & 2 & 1 & 1 & 2 & 0.755 & 1.124 \\
\hline & SD & & & & & & 0.257 & 0.052 \\
\hline & LB & & & & & & 0.274 & 1.025 \\
\hline & UB & & & & & & 1.289 & 1.221 \\
\hline & IACT & & & & & & 199.5 & 317.1 \\
\hline \multicolumn{2}{|c|}{ Persistence } & - & 0.942 & 0.772 & 0.900 & 0.760 & - & 0.945 \\
\hline \multicolumn{2}{|c|}{$\begin{array}{c}\text { Conditional } \\
\text { DIC (SD) }\end{array}$} & $\begin{array}{c}3244.0 \\
(0.04)\end{array}$ & $\begin{array}{c}3201.9 \\
(0.28)\end{array}$ & $\begin{array}{c}3178.6 \\
(0.12)\end{array}$ & $\begin{array}{c}3210.8 \\
(0.57)\end{array}$ & $\begin{array}{l}3181.3 \\
(0.12)\end{array}$ & $\begin{array}{c}3235.9 \\
(0.19)\end{array}$ & $\begin{array}{l}3176.3 \\
(0.24)\end{array}$ \\
\hline \multirow{2}{*}{\multicolumn{2}{|c|}{$\begin{array}{c}\text { pD } \\
\text { Rank }\end{array}$}} & 2 & 3 & 4 & 3 & 4 & 3 & 5 \\
\hline & & 7 & 4 & 2 & 5 & 3 & 6 & 1 \\
\hline
\end{tabular}

Source: Authors' calculation from IDR/JPY returns.

Regarding the Taylor effect, the NARCH and APARCH models are considered. In the IDR/EUR case, the Taylor parameter $(\delta)$ is significantly different from 1 (even in terms of the 99\% HPD interval) but not from 2 in the NARCH model and significantly different from 1 or 2 in the APARCH model. In the IDR/JPY case, the Taylor parameter is significantly different from 2 but not from 1 in the NARCH model and significantly different from 1 or 2 in the APARCH model. We even found that the 99\% HPD interval of $\delta$ does not include 1 or 2 for the APARCH model adopting the JPY returns (results not shown). Meanwhile, in the IDR/USD case, the Taylor parameter is significantly different from 1 or 2 in both NARCH and APARCH models. In general, these deviations imply the presence of Taylor effect in all observed data.

Tables 4-6 also report the volatility persistence values computed as $\alpha+\beta$ for the GARCH and TS-GARCH models, $\alpha+0,5 \gamma+\beta$ for the TARCH and GJRGARCH models, and $\alpha(1-\gamma)^{\delta}+\beta$ for the APARCH model. According to Campbell et al. (1996), the volatility persistence measures how fast (or slow) the volatility reverts or decay towards its mean. A high persistence (greater than 0 but less than 1) implies slow reversion to the mean. In this study, the highest volatility persistences are found in the GARCH model adopting IDR/EUR returns and in the APARCH model adopting IDR/JPY and IDR/USD returns. Notice that the persistence measures fall close to one for the IDR/EUR returns in the GARCH model only, for the IDR/JPY returns in the GARCH, TS-GARCH, APARCH models, and for the IDR/USD returns in all models. We conclude that volatility in the USD returns is highly persistent. 
Table 6. Results of MCMC estimation for the models adopting IDR/USD returns, the conditional DIC estimates, and the $\mathrm{pD}$ (effective number of parameters) estimates.

\begin{tabular}{|c|c|c|c|c|c|c|c|c|}
\hline \multirow{2}{*}{\multicolumn{2}{|c|}{$\begin{array}{l}\text { Para- Statistics } \\
\text { meter }\end{array}$}} & \multicolumn{7}{|c|}{ Model } \\
\hline & & ARCH & GARCH & TARCH & $\begin{array}{c}\text { TS- } \\
\text { GARCH }\end{array}$ & $\begin{array}{c}\text { GJR- } \\
\text { GARCH }\end{array}$ & NARCH & APARCH \\
\hline \multirow[t]{5}{*}{$\omega$} & Mean & 0.112 & 0.007 & 0.023 & 0.054 & 0.006 & 0.213 & 0.016 \\
\hline & SD & 0.006 & 0.001 & 0.004 & 0.007 & 0.001 & 0.041 & 0.010 \\
\hline & LB & 0.100 & 0.004 & 0.015 & 0.041 & 0.004 & 0.142 & 0.001 \\
\hline & UB & 0.124 & 0.010 & 0.032 & 0.067 & 0.008 & 0.296 & 0.038 \\
\hline & IACT & 7.6 & 105.7 & 111.9 & 248.3 & 58.4 & 235.2 & 404.9 \\
\hline \multirow[t]{5}{*}{$\alpha$} & Mean & 0.569 & 0.198 & 0.231 & 0.177 & 0.206 & 0.491 & 0.218 \\
\hline & SD & 0.067 & 0.026 & 0.021 & 0.022 & 0.027 & 0.051 & 0.024 \\
\hline & LB & 0.437 & 0.148 & 0.191 & 0.134 & 0.160 & 0.387 & 0.172 \\
\hline & UB & 0.695 & 0.249 & 0.273 & 0.219 & 0.246 & 0.592 & 0.265 \\
\hline & IACT & 6.9 & 160.7 & 133.1 & 227.1 & 64.7 & 71.9 & 476.0 \\
\hline \multirow[t]{5}{*}{$\beta$} & Mean & 0 & 0.784 & 0.782 & 0.787 & 0.791 & 0 & 0.750 \\
\hline & SD & & 0.026 & 0.020 & 0.024 & 0.022 & & 0.028 \\
\hline & LB & & 0.730 & 0.746 & 0.738 & 0.756 & & 0.690 \\
\hline & UB & & 0.833 & 0.825 & 0.830 & 0.826 & & 0.794 \\
\hline & IACT & & 160.8 & 168.1 & 263.2 & 82.3 & & 496.0 \\
\hline \multirow[t]{5}{*}{$\gamma$} & Mean & 0 & 0 & -0.152 & 0 & -0.129 & 0 & -0.100 \\
\hline & SD & & & 0.035 & & 0.038 & & 0.047 \\
\hline & LB & & & -0.225 & & -0.191 & & -0.193 \\
\hline & UB & & & -0.085 & & -0.065 & & -0.014 \\
\hline & IACT & & & 7.6 & & 7.4 & & 129.6 \\
\hline \multirow[t]{5}{*}{$\delta$} & Mean & 2 & 2 & 1 & 1 & 2 & 1.368 & 0.913 \\
\hline & SD & & & & & & 0.196 & 0.031 \\
\hline & LB & & & & & & 1.010 & 0.857 \\
\hline & UB & & & & & & 1.745 & 0.984 \\
\hline & IACT & & & & & & 229.1 & 217.1 \\
\hline \multicolumn{2}{|c|}{ Persistence } & - & 0.983 & 0.937 & 0.966 & 0.933 & - & 0.989 \\
\hline \multicolumn{2}{|c|}{$\begin{array}{l}\text { Conditional } \\
\text { DIC (SD) }\end{array}$} & $\begin{array}{l}1520.4 \\
(0.02)\end{array}$ & $\begin{array}{c}1336.8 \\
(0.16) \\
\end{array}$ & $\begin{array}{c}\mathbf{1 3 2 2 . 4} \\
(0.14)\end{array}$ & $\begin{array}{c}1400.4 \\
(0.18)\end{array}$ & $\begin{array}{c}1326.9 \\
(0.07) \\
\end{array}$ & $\begin{array}{l}1519.0 \\
(0.25)\end{array}$ & $\begin{array}{r}1336.4 \\
(0.33)\end{array}$ \\
\hline \multicolumn{2}{|c|}{ pD } & 2 & 3 & 4 & 3 & 4 & 3 & 7 \\
\hline \multicolumn{2}{|c|}{ Rank } & 7 & 4 & 1 & 5 & 2 & 6 & 3 \\
\hline
\end{tabular}

Source: Authors' calculation from IDR/USD returns.

In general, the estimation results related to the leverage and Taylor effects suggest that the APARCH model fits the IDR/JPY and IDR/USD returns. This results are confirmed by DIC value for the IDR/JPY returns only. Meanwhile, in the IDR/USD case, the DIC value suggests that the TARCH model provides the best fit among all competing models. It means that the leverage effect is only suggested to be accommodated into the IDR/USD returns. In the IDR/EUR case, the DIC value suggests that the GARCH model provides the best fit.

On the basis of the best fitting models, volatility models for the IDR/EUR, IDR/JPY, and IDR/USD returns are now respectively expressed by

$$
\begin{gathered}
\sigma_{t}^{2}=0.027+0.056 R_{t-1}+0.884 \sigma_{t-1}^{2}, \\
\sigma_{t}^{1.124}=0.127+0.121\left(\left|R_{t-1}\right|+0.363 R_{t-1}\right)^{1.124}+0.753 \sigma_{t-1}^{1.124}, \\
\sigma_{t}=0.023+0.231\left(\left|R_{t-1}\right|+0.152 R_{t-1}\right)+0.782 \sigma_{t} .
\end{gathered}
$$

Figure 2 presents the time series plots of the variance (squared volatility) for the above models. Comparing Figure 1 and Figure 2 shows that a large piece of returns (positive or negative) leads to a high volatility and a small piece of returns 
leads to a low volatility, indicating volatility clustering. In particular, in the IDR/EUR case, the periods of high volatility occurred in May 2010, September and October 2011, June 2012, December 2014, and August to December 2015. For the IDR/JPY returns, volatility was high in January 2010, May 2010, June 2013, and December 2014. Finally, the IDR/USD returns have high volatility in September to October 2011 and October 2015.
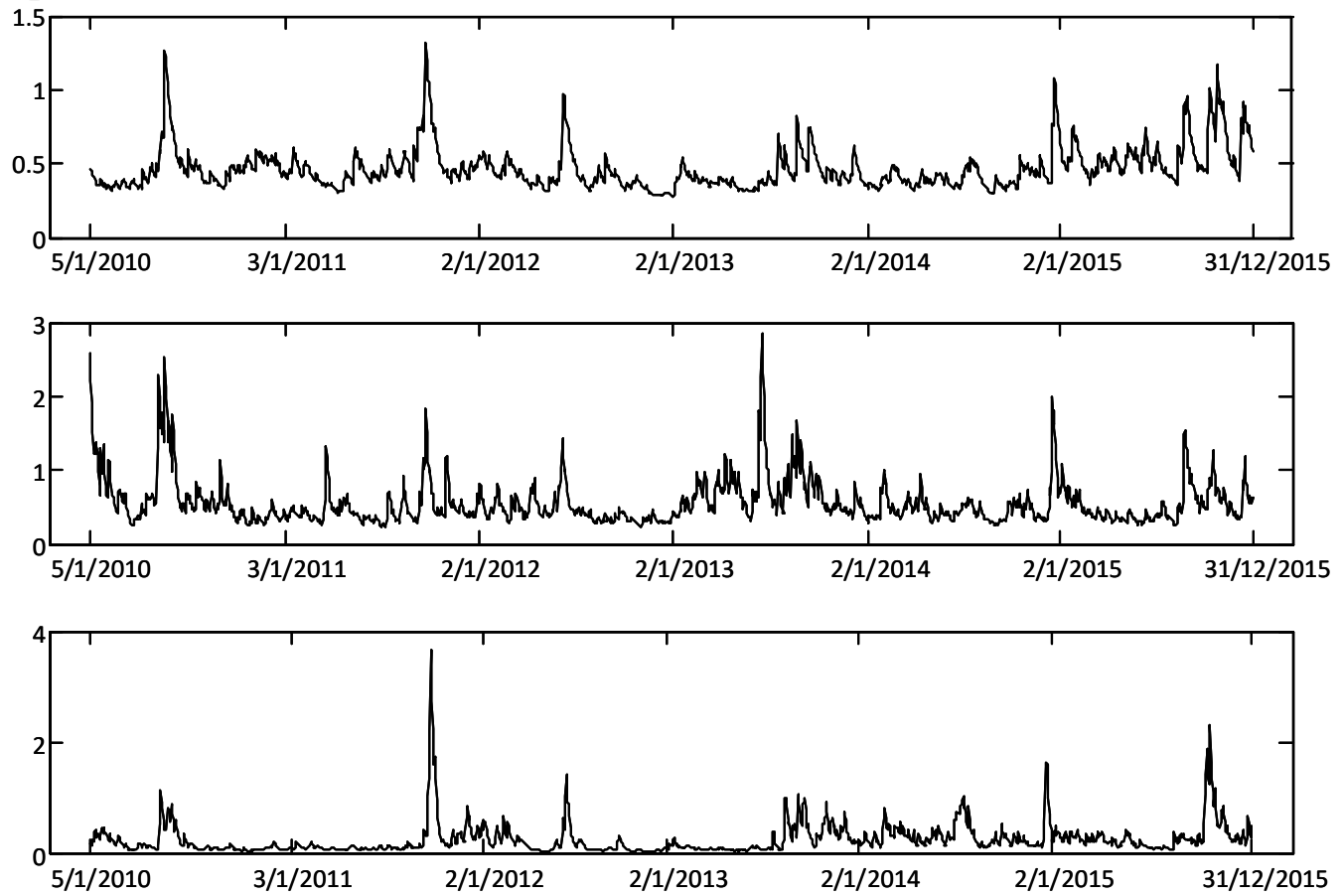

Figure 2. Time series plots for daily variance of the IDR/EUR (top), IDR/JPY (middle), and IDR/USD (bottom) returns estimated from the GARCH, APARCH, and TARCH models, respectively.

Source: Authors' calculation.

\section{CONCLUSION}

This study compared several APARCH $(1,1)$-type models, including the ARCH, GARCH, TARCH, TS-GARCH, GJR-GARCH, NARCH, and APARCH models. These models were applied to the daily returns of the EUR, JPY, and USD selling exchange rate to the IDR covering the period of January 2010 to 2015. The empirical results demonstrated that the GARCH, APARCH, and TARCH models best fitted to the EUR, JPY, and USD data.

\section{FUTURE WORK}

Future work may explore the non-normality of exchange rate returns as in many studies and reviews. Among the well-known ones are Student- $t$ distribution and generalized Student- $t$ distributions (e.g., see Nugroho et al. $(2014,2016)$ ).

\section{REFERENCES}

Abdalla, S.Z.S., \& Winker, P. (2012). Modelling stock market volatility using univariate GARCH models: Evidence from Sudan and Egypt. International Journal of Economics and Finance, 4(8), 161-176.

Atachade, Y.F., \& Rosenthal, J.S. (2005). On adapative Markov Chain Monte Carlo algorithms. Bernoulli, 11(5), 815-828. 
Bollerslev, T. (1986). Generalized autoregressive conditional heteroskedasticity. Journal of Econometrics, 31, 307-327.

Campbell, J.Y., Lo, A.W., \& MacKinlay, A.C. (1996). The Econometrics of Financial Markets. Princeton University Press.

Danielsson, J. (2011). Financial Risk Forcasting. John Wiley \& Sons.

Dickey, D.A., \& Fuller, W.A. (1981). Distribution of the estimators for autoregressive time series with a unit root. Econometrica, 49, 1057-1072.

Ding, Z., Granger, C.W., \& Engle, R.F. (1993). A long memory property of stock market returns and a new model. Journal of Empirical Finance, $1(1), 83-106$.

Laurent, S. (2004). Analytical derivates of the APARCH model. Computational Economics, 24, (1), 51-57.

Longmore, R., \& Robinson, W. (2004). Modelling and Forecasting Exchange Rate Dynamics: An Application of Asymmetric Volatility Models. Bank of Jamaica. Working Paper WP2004/03.

Nugroho, D.B., \& Morimoto, T. (2014). Realized non-linear stochastic volatility models with asymmetric effects and generalized Student's $t$ distributions. Journal of the Japan Statistical Society, 44 (1), 83-118.

Nugroho, D.B., \& Morimoto, T. (2015). Estimation of realized stochastic volatility models using Hamiltonian Monte Carlo-based methods. Computational Statistics, 30(2), 491-516.

Nugroho, D.B., \& Morimoto, T. (2016). Box-Cox realized asymmetric stochastic volatility models with generalized Student's t-error distributions. Journal of Applied Statistics, 43(10), 1906-1927.

Roberts, G.O., \& Rosenthal, J.S. (2009). Examples of Adaptive MCMC. Journal of Computational and Graphical Statistics, 18(2), 349-367.

Ruppert, D. (2011). Statistics and data analysis for financial engineering. New York: Springer.

Safrudin, I.M., Nugroho, D.B. \& Setiawan, A. (2015). Estimasi berbasis MCMC untuk returns volatility di pasar valas Indonesia melalui model ARCH [MCMC-based estimation for returns volatility in the Indonesian foreign exchange market through ARCH model]. Prosiding Sendika FKIP UMP, $1,(1), 29-33$.

Salim, F.C., Nugroho, D.B. \& Susanto, A. (2016). Model volatilitas GARCH(1,1) dengan error Student- $t$ untuk kurs beli EUR dan JPY terhadap IDR [GARCH $(1,1)$ volatility model with Student-t error for the EUR and JPY buying rates to IDR]. Jurnal MIPA, 39(1), 63-69.

Salvatore, D. (2013). International Economics (11th ed.). Fordham University.

Saputri, E.D., Nugroho, D.B. \& Setiawan, A. (2016). Model volatilitas ARCH(1) dengan returns error berdistribusi skewed Student- $t$ [ARCH(1) volatility model with Student-t returns error distribution]. Jurnal MIPA, 39 (1), 78-84.

Taylor, S. (1986). Modelling Financial Time Series. New York: John Wiley \& Sons.

Tsay, R.S. (2005). Analysis of financial time series (2nd ed.). New Jersey: John Wiley \& Sons.

Engle, R. F. (1982). Autoregressive conditional heteroscedasticity with estimates of the variance of United Kingdom inflation. Econometrica: Journal of the Econometric Society, 987-1007. 